\title{
Genetic diversity of Ixora macrophylla Bartl. and Ixora auriculata Elmer (Rubiaceae) inferred from nrDNA (ITS) and cpDNA (trnL-f)
} sequence data

\author{
Raphael Paolo A. Casipit ${ }^{1}$, Carl Anton D. Canlas ${ }^{1}$, Mary Elizabeth C. Legarda ${ }^{1}$, Justinne R. Yap ${ }^{1}$, \\ Sarah Grace S. Zamudio ${ }^{2}$, and Cecilia I. Banag-Moran ${ }^{1,2,3^{*}}$
}

\begin{abstract}
This study aims to assess the intraspecific genetic diversity of Ixora macrophylla, a widespread species of Philippine Ixora recorded from several islands of the Philippines, and I. auriculata, an endemic species that has yet to be included in molecular studies of the Philippine Ixora. The number of haplotypes, haplotype diversity, and nucleotide diversity of 19 trnL-F and 17 ITS sequences of I. macrophylla, as well as 4 trnL-F and 4 ITS sequences of $I$. auriculata were obtained using DNAsp 5.10.1 software, and pairwise distances were calculated using the nucleotide Kimura 2-parameter using MEGA 6.06. Two haplotypes of trnL-F and nine haplotypes of ITS were identified in six populations of I. macrophylla. One of the two haplotypes of $\operatorname{trn} \mathrm{L}-\mathrm{F}$ was unique to the Mindoro population. One of the nine haplotypes of ITS was common among seven individuals from four populations. Intraspecific pairwise distances ranged from 0 to $0.1 \%$ for $\operatorname{trn} \mathrm{L}$ $\mathrm{F}$ and 0 to $0.9 \%$ for ITS. Mantel test showed weak correlations between the genetic and geographic distances for both $\operatorname{trn} \mathrm{L}-\mathrm{F}(\mathrm{r}=-0.0380)$ and ITS $(\mathrm{r}=0.0980)$ sequences. For the genetic diversity of I. auriculata, two haplotypes of $\operatorname{trn} \mathrm{L}-\mathrm{F}$ and four haplotypes of ITS were identified, with intraspecific pairwise distances ranging from 0 to $0.1 \%$ in $\operatorname{trn} \mathrm{L}-\mathrm{F}$ and 0.3 to $3.5 \%$ in ITS. The results for genetic diversity may be used to better understand the population genetics of the Philippine Ixora and provide insights for conservation.
\end{abstract}

Keywords: haplotype, nucleotide diversity, pairwise distances, phylogenetic analyses, population genetics

\section{Introduction}

Genetic diversity is represented by the gene pool, or the variation in genes, within and among populations (Rao \& Hodgkin, 2001), and is influenced by factors such as natural selection, mutations, gene flow, and genetic drift (Amos \& Harwood, 1998). Investigating the genetic diversity of species can reveal the patterns of gene flow among existing populations (Mason-Gamer et al., 1995). Geographical range is also an important factor in high genetic diversity among populations, as geographical isolation restricts the occurrence of gene flow among populations (Maki et al., 2003). A high population

\footnotetext{
${ }^{1}$ Department of Biological Sciences, College of Science University of Santo Tomas, España Boulevard, 1015 Manila, Philippines

${ }^{2}$ The Graduate School, University of Santo Tomas, España Boulevard, 1015 Manila, Philippines

${ }^{3}$ Research Centre for the Natural and Applied Sciences, University of Santo Tomas, España Boulevard, 1015 Manila, Philippines.

*Corresponding email: cibanag@ust.edu.ph

Date Submitted: 31 July 2019

Date Accepted: 04 May 2020
}

genetic diversity in abundant species within populations can be associated with larger population sizes, and high rates of gene flow with other populations (Hague \& Routman, 2016). Genetic diversity has significant implications to conservation and speciation, as it is linked to the adaptability of species and their populations to cope with environmental stresses (Frankham, 2005), and can drive the evolution of species through natural selection. With climate change being a primary concern for ecologists, the capability of species to adapt to environmental changes is a necessity for their survival.

The Philippines is considered a leading biological hotspot, as it supports a significant number of endemic flora and fauna (Myers et al., 2000) and, as an archipelago, serves as a valuable model for studies concerning phylogenetics and population genetics (Brown et al., 2013). Among the diverse flora are the endemic species of the pantropical genus Ixora L. With approximately 530 species worldwide and 30 out of 41 Philippines species are endemic (Alejandro, 2007), Ixora is the third largest genus under the Rubiaceae which grows predominantly in low- to mid-altitude humid rainforests (Davis et al., 2009). With its tropical nature, the Philippines provides a suitable environment for the propagation of such species. Recent 


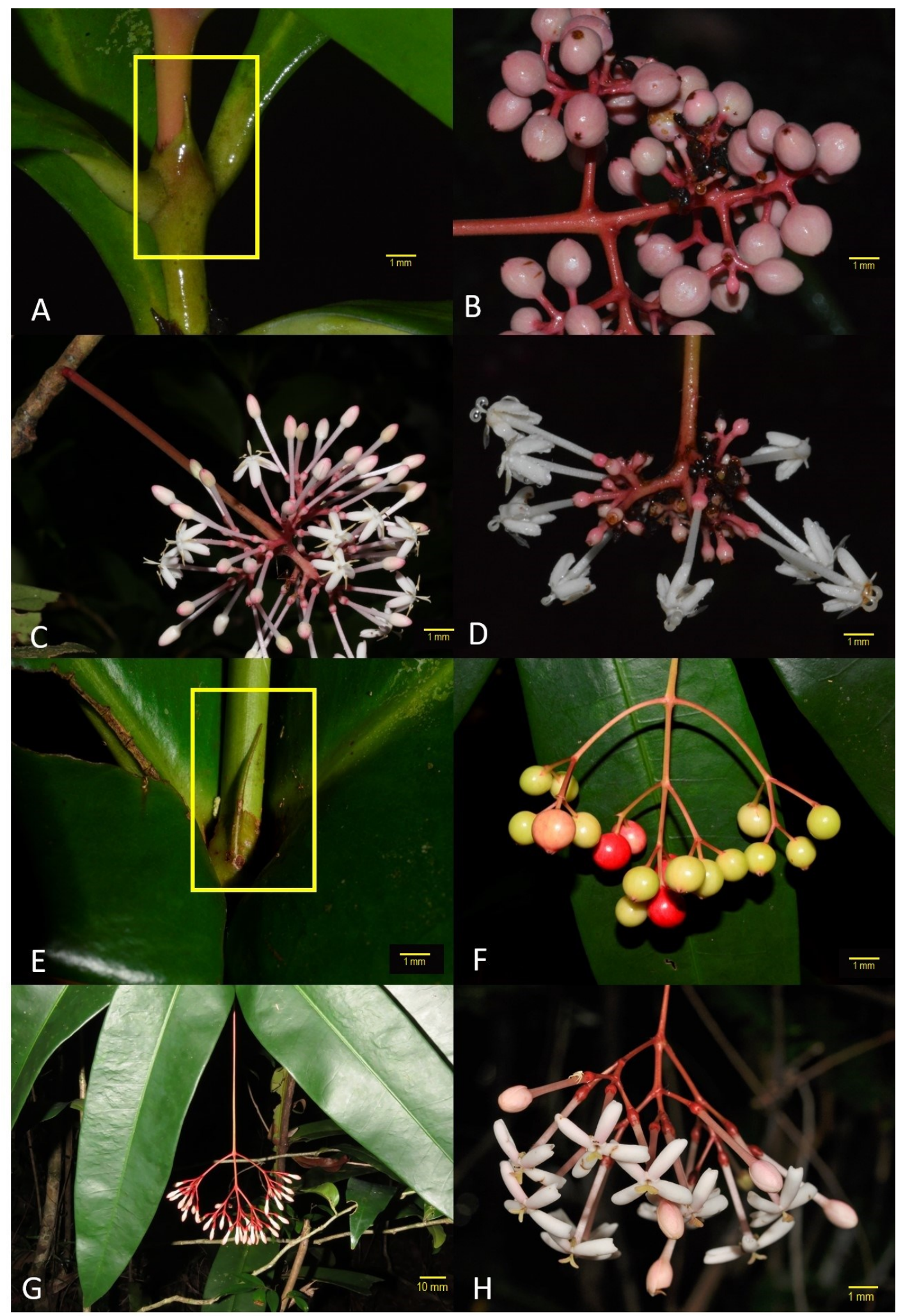

Figure 1. Ixora macrophylla (Cagayan) -(A) stipule, (B) infructuscence, (C) cauliflorous inflorescence (D) inflorescence with open flowers. Ixora auriculata (Bulacan)- E. stipule, (B) infructuscence, (C) terminal inflorescence (D) inflorescence with open flowers. Photos taken by Sarah Grace S. Zamudio (A-D), Cecilia I. Banag (E-G), and Pieter B. Pelser \& Julie F. Barcelona (H). Scale bars: $1 \mathrm{~mm}(\mathrm{~A}-\mathrm{F}, \mathrm{H}) ; 10 \mathrm{~mm}(\mathrm{G})$. 
studies on the molecular phylogeny and biogeographical patterns of Philippine Ixora showed that its polyphyly is attributed to at least five colonization events, of which one lineage is derived from species from Wallacea, and the remaining four lineages related to species from Asia. The incongruence between the topologies of nuclear and chloroplast datasets characterized the complex evolutionary history of the Philippine Ixora. Furthermore, the close relationship between widespread species and locally adapted narrow endemics suggests that the widespread species serve as pools from which speciation takes place (Banag et al., 2017).

Ixora macrophylla Bartl. (Figs. 1A-C) is endemic to the Philippines and is widely distributed in most islands and provinces of Luzon, Visayas, and Mindanao. This species can be distinguished from other Philippine Ixora primarily through its cauliflorous inflorescences, a unique feature in the genus, whose inflorescence is usually terminal. Ixora auriculata Elmer (Figs. 1D-G) is endemic only to several provinces in Luzon. It

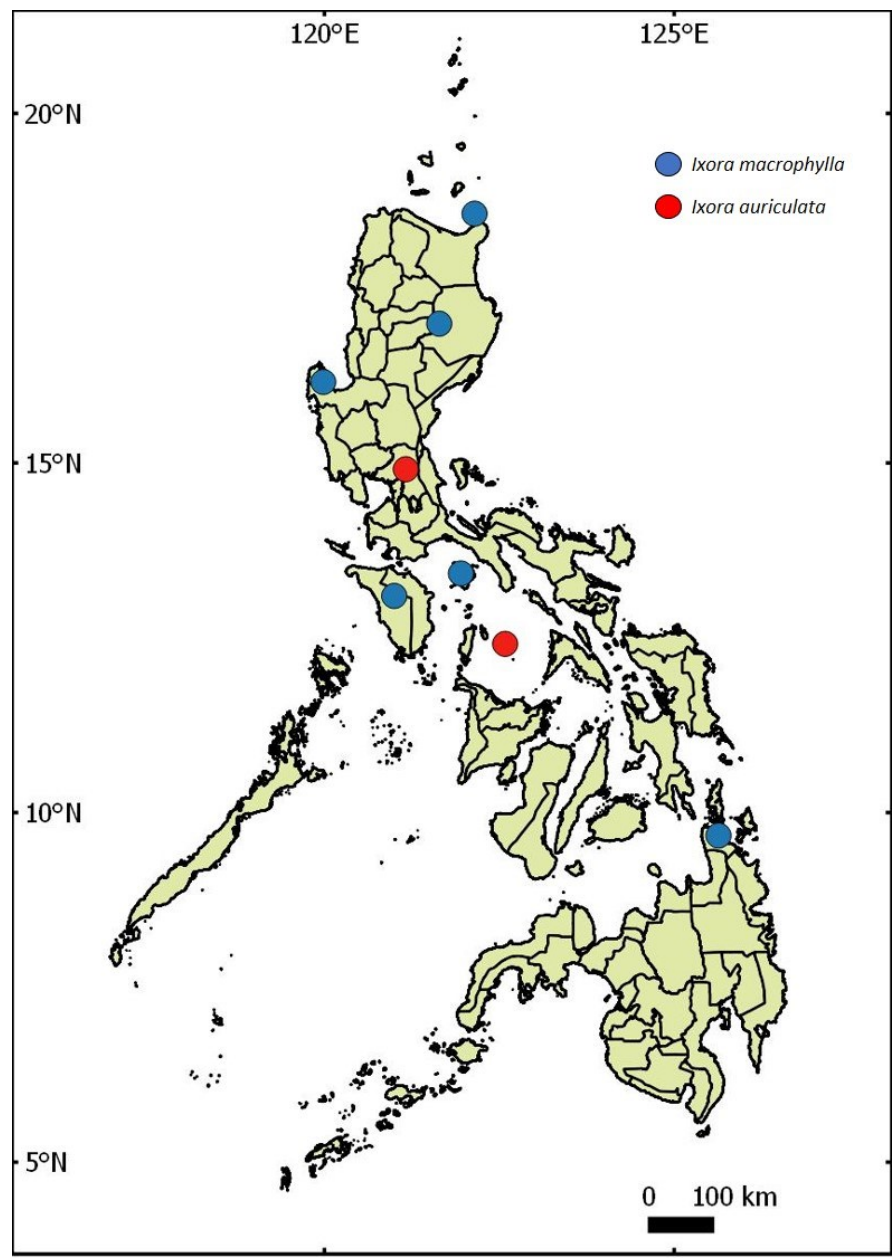

Figure 2. Map of the Philippines with marked localities where the utilized samples were collected. is characterized by its sessile leaves with cordate or auriculate bases, pendulous inflorescences, and white corollas.

Since I. macrophylla have a wider distribution in the Philippines compared with other single island endemics, often their conservation is not a major concern for policy makers. However, these widespread species can provide opportunities to investigate the population genetics of endemic Ixora in the Philippine archipelago. The purpose of this research is to provide baseline information on the genetic diversity of $I$. macrophylla among six populations namely; Cagayan, Pangasinan, Aurora, Marinduque, Occidental Mindoro, and Surigao del Norte. The chosen populations are representative throughout the Philippines to maximize geographical distances.

In the recent molecular study on Philippine Ixora, some endemic species such as I. auriculata were not included in the phylogenetic analysis due to lack of available leaf material. Recent field collections conducted in two localities; Angat, Bulacan and Sibuyan Island, Romblon by the Thomasian Angiosperm Barcoding and Phylogeny Group (TAPBG) resulted in the recollection of Ixora species identified as $I$. auriculata based on morphology. However, after thorough examination of the reproductive parts of the samples from Angat and Sibuyan, several differences mostly in the color and measurements of the inflorescence axes were observed raising the question whether the samples from these localities are conspecific or not. To date, molecular data on I. auriculata have yet to be produced.

Thus, the objective of this study is to assess the intraspecific genetic diversity of the six I. macrophylla populations and the two $I$. auriculata populations using the nuclear ribosomal marker internal transcribed spacer (ITS) and the chloroplast marker trnL-F.

\section{Materials and Methods}

\section{Taxon sampling}

Fieldworks were conducted in different provinces of the Philippines (Fig. 2) after securing Gratuitous permits and Local transport permits from the Department of Environment and Natural Resources (DENR), City Environment and Natural Resource Office (CENRO) and Provincial Environment and Natural Resource Office (PENRO) to collect plant samples of $I$. macrophylla and I. auriculata. The fruits and flowers were preserved in $70 \%$ ethyl alcohol for storage and leaf samples used for molecular analyses were preserved in silica gel (Chase \& Hills, 1991). The herbarium specimens were mounted onto herbarium sheets and deposited at the University of Santo Tomas Herbarium (USTH) for accessioning. Refer to Appendix 1 (List of herbarium specimens examined). 
Table 1. Primers used in the amplification of nuclear and chloroplast regions

\begin{tabular}{llll}
\hline Region & Primer & Primer Sequence (5' -> 3') $^{\prime}$ & Reference \\
\hline ITS & P16F & TCACTGAACCTTATCATTTAGAGGA & Popp \& Oxelman, 2001 \\
& P25R & GGGTAGTCCCGCCTGACCTG & \\
\multirow{2}{*}{$n n$ L-F } & C & CGAAATCGGTAGACGCTACG & Taberlet et al., 1991 \\
& F & ATTTGAACTGGTGACACGAG & \\
\hline
\end{tabular}

\section{DNA Extraction, Amplification, Purification, and Sequencing}

Leaves stored in silica gel were homogenized into powder using an Omni Bead Ruptor. Genomic DNA was extracted from dried leaf samples using the DNeasy Plant Mini Kit (Qiagen, Germany) by following the protocol recommended by the manufacturer. The desired markers were amplified through polymerase chain reaction (PCR) using the Biometra T Gradient thermocycler. Both the ITS and trnL-F gene regions were amplified from extracted DNA of I. macrophylla and $I$. auriculata (Table 1). The amplicons were subjected to agarose gel electrophoresis to confirm the presence of DNA bands. The amplified PCR products were purified using QIAquick Purification Kit (Qiagen, Germany) following the protocol provided by the manufacturer. The purified DNA samples were then sent to Macrogen Inc. (South Korea) for bidirectional sequencing. The sequences were assembled using CodonCode Aligner v7.1.1 (CodonCode Co. USA), and ambiguous bases were manually edited based on readings of the electropherogram. The sequences were manually aligned using Mesquite v3.51 (Maddison \& Maddison, 2018).

\section{Statistical analyses}

For the genetic and statistical analyses, the ITS and trnL-F sequences of I. macrophylla generated in this study were added to the sequences of I. macrophylla that were collected from Aurora, Occidental Mindoro, and Surigao del Norte used in the preliminary study conducted by Gaticales et al. (2016). The number of haplotypes (h), haplotype diversity, (Hd) and nucleotide diversity $(\pi)$ within and among populations of $I$. macrophylla was determined using DnaSP version 5.10.1 (Librado \& Rozas, 2009). Pairwise distances of I. macrophylla were calculated using the nucleotide Kimura 2-parameter model using MEGA version 6.0 (Tamura et al., 2013). The same analyses were conducted with the two populations of $I$. auriculata collected from Bulacan and Romblon.

The correlation between genetic and geographic distances of I. macrophylla populations was evaluated using the Mantel test. For the first matrix, pairwise genetic distances of the 19 individuals from the 782 base pairs (bp) of trnL-F and 17 individuals from the $674 \mathrm{bp}$ for ITS were computed as implemented in MEGA v6.06. The geographic distances between the collection sites were computed with an Excel macro for the Vincenty formula (Dalgleish, 2015), obtaining a second matrix. Correlations and the Mantel test with 999 iterations were calculated with the ExtraStats function in Poptools version 3.2.5 (Hood, 2010). Mantel test was not done for I. auriculata study since only two populations were included in this study.

\section{Results}

\section{Genetic diversity of I. macrophylla}

This study used a total of 19 trnL-F sequences and 17 ITS sequences obtained from six different populations of $I$. macrophylla. Of these, eight trnL-F and eight ITS sequences are newly generated in this study. Two haplotypes were identified in the $\operatorname{trn} \mathrm{L}-\mathrm{F}$ sequences, while nine haplotypes were found in the ITS sequences. One of the haplotypes for trnL-F was common among all the individuals of five populations: Cagayan, Pangasinan, Aurora, Marinduque, and Surigao, while the other haplotype was restricted to all samples from the Mindoro population. One of the haplotypes for ITS was common among seven individuals overall: two individuals from Cagayan, two from Marinduque, one from Mindoro, and two from Surigao. Another haplotype is common among all individuals of the Pangasinan population. The rest of the individuals, particularly the three from Aurora, one from Cagayan, two from Mindoro, and one from Surigao all possess their own unique haplotypes.

The average haplotype diversity for the trnL-F sequences was 0.28070 , while the average haplotype diversity for the ITS sequences was 0.82353 . There is no haplotype diversity for the trnL-F sequences within populations. On the other hand, ITS sequences are generally more genetically diverse, ranging from 0 (Pangasinan and Marinduque) to 1 (Aurora and Mindoro). The nucleotide diversity for the $\operatorname{trn} \mathrm{L}-\mathrm{F}$ sequences is 0 within all populations yet yielded a value of 0.00036 among the populations. Nucleotide diversity of the ITS sequences ranged from 0 (Pangasinan and Marinduque) to 0.00405 (Aurora), with an overall value of 0.00284 . The data for the genetic diversity of the six I. macrophylla populations are summarized in Table 2. The pairwise distance of the $I$. macrophylla sequences ranged from 0 to $0.1 \%$ in $\operatorname{trn} \mathrm{L}-\mathrm{F}$, and 0 
to $0.9 \%$ in ITS. The smallest value of 0 was usually observed between samples within populations.

\section{Mantel Test}

The Mantel test between the genetic and geographic distances of $I$. macrophylla resulted to a weak negative correlation coefficient of -0.0380 for trnL-F and a weak positive correlation coefficient of 0.0980 for ITS (Table 3). As represented by the diamonds in the charts (Fig. 3), both values for the correlation coefficient fall within the $95 \%$ confidence interval of -0.1668 to 0.2528 (trnL-F) and -0.3413 to 0.3516 (ITS).

\section{Genetic diversity of I. auriculata}

A total of four trnL-F and four ITS sequences of $I$. auriculata were generated. Two haplotypes were retrieved from the trnL-F sequences, while four haplotypes were identified from the ITS sequences. One of the two haplotypes of trnL-F was common among two individuals from Bulacan and one from Romblon, while the other haplotype was unique to one individual from Romblon. On the other hand, all four individuals possess unique haplotypes for ITS. The average values of haplotype diversity for both datasets are 0.5 for $t r n \mathrm{~L}-\mathrm{F}$ and 1 for ITS. The haplotype diversity for the trnL-F sequences was 0 for the Bulacan samples, and 1 for Romblon samples, while the haplotype diversity for the ITS sequences yielded a value of 1 for both the Bulacan and Romblon samples. The data are summarized in Table 4.

The pairwise differences of the I. auriculata sequences ranged from 0 to $0.1 \%$ in trnL-F and $0.3 \%$ to $3.2 \%$ in ITS. The mean genetic distances of ITS were $0.45 \%$ within populations and $3.05 \%$ between the two populations. For $\operatorname{trn} \mathrm{L}-\mathrm{F}$, the smallest value of 0 was observed among the two individuals of Bulacan and one individual of Romblon, while the value of $0.1 \%$ was obtained between one of the Romblon individuals and

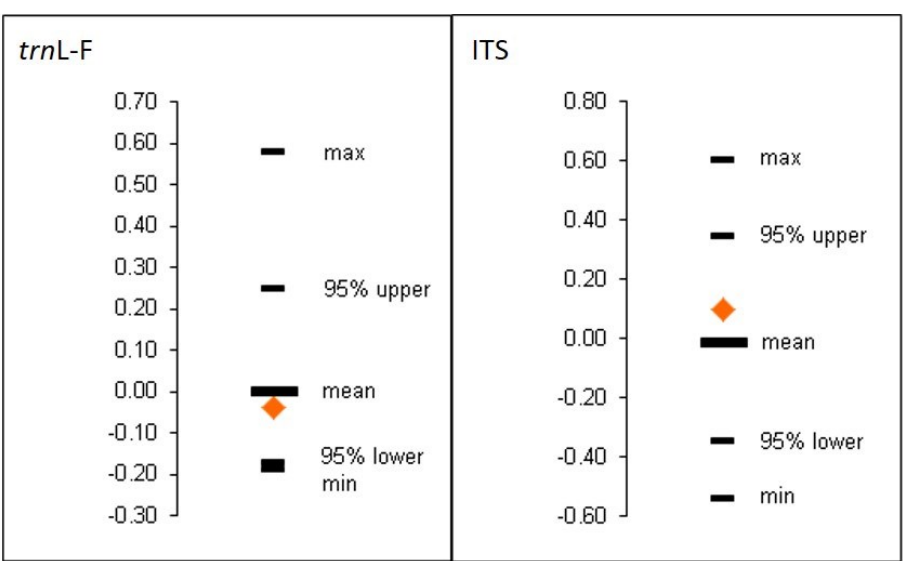

Figure 3. Chart representation of the Mantel test results for $\operatorname{trn} L-F$ (left) and ITS (right) sequences of I. macrophylla

all other individuals. For ITS, smaller values (0.3-0.6\%) were observed between individuals of the same population, while larger values (2.9-3.2\%) were detected between individuals from different populations.

\section{Discussion}

\section{Genetic diversity of I. macrophylla}

Haplotypes, or sets of alleles that are inherited together from a single parent, can be used in inferring patterns of gene flow among populations (Templeton, 2004). The number of haplotypes for the trnL-F region of I. macrophylla is relatively lower compared to that of their ITS. Among all 19 individuals, 16 share a common haplotype, which include the samples from Cagayan, Pangasinan, Aurora, Marinduque, and Surigao. This is evidence that gene flow had occurred among these five populations. The other haplotype is restricted to the three samples from Mindoro. The low haplotype diversity of trnL-F can be associated with its less variation and lower substitution rates (Andreasen et al., 1999; Dong et al., 2012). Despite its

Table 2. Genetic diversity of the six I. macrophylla populations

\begin{tabular}{|c|c|c|c|c|c|c|c|c|c|c|}
\hline & A. $\operatorname{trn} \mathrm{L}-\mathrm{F}$ & & & & & B. ITS & & & & \\
\hline Group & $\begin{array}{c}\text { No. of } \\
\text { sequences }\end{array}$ & $\begin{array}{c}\text { No. of } \\
\text { haplotypes }\end{array}$ & $\begin{array}{c}\text { Haplotype } \\
\text { diversity } \\
\text { Hd }\end{array}$ & $\begin{array}{l}\text { Ave. no. of } \\
\text { differences, } \\
\text { K }\end{array}$ & $\begin{array}{l}\text { Nucleotide } \\
\text { diversity, pi }\end{array}$ & $\begin{array}{c}\text { No. of } \\
\text { sequences }\end{array}$ & $\begin{array}{c}\text { No. of } \\
\text { haplotypes }\end{array}$ & $\begin{array}{c}\text { Haplotype } \\
\text { diversity } \\
\text { Hd }\end{array}$ & $\begin{array}{l}\text { Ave. no. of } \\
\text { differences, } \\
\text { K }\end{array}$ & $\begin{array}{l}\text { Nucleotide } \\
\text { diversity, pi }\end{array}$ \\
\hline Cagayan & 3 & 1 & 0.00000 & 0.00000 & 0.00000 & 3 & 2 & 0.66667 & 2.00000 & 0.00304 \\
\hline Pangasinan & 3 & 1 & 0.00000 & 0.00000 & 0.00000 & 3 & 1 & 0.00000 & 0.00000 & 0.00000 \\
\hline Aurora & 4 & 1 & 0.00000 & 0.00000 & 0.00000 & 3 & 3 & 1.00000 & 2.66667 & 0.00405 \\
\hline Marinduque & 2 & 1 & 0.00000 & 0.00000 & 0.00000 & 2 & 1 & 0.00000 & 0.00000 & 0.00000 \\
\hline Mindoro & 3 & 1 & 0.00000 & 0.00000 & 0.00000 & 3 & 3 & 1.00000 & 2.00000 & 0.00304 \\
\hline Surigao & 4 & 1 & 0.00000 & 0.00000 & 0.00000 & 3 & 2 & 0.66667 & 0.66667 & 0.00101 \\
\hline Total Data & 19 & 2 & 0.28070 & 0.28070 & 0.00036 & 17 & 9 & 0.82353 & 1.86765 & 0.00284 \\
\hline
\end{tabular}


Table 3. Results of the Mantel test for I. macrophylla populations

\begin{tabular}{|c|c|c|c|c|c|}
\hline A. $\operatorname{trn} \mathrm{L}-\mathrm{F}$ & & & A. ITS & & \\
\hline $\begin{array}{l}\text { Correlation between } \\
\text { matrices }\end{array}$ & & & $\begin{array}{l}\text { Correlation between } \\
\text { matrices }\end{array}$ & & \\
\hline $\mathrm{r}=$ & -0.0380 & & $\mathrm{r}=$ & 0.0980 & \\
\hline $\begin{array}{l}\text { Randomized Matrices } \\
\text { (999 runs) }\end{array}$ & & & $\begin{array}{l}\text { Randomized Matrices } \\
\text { (999 runs) }\end{array}$ & & \\
\hline $\mathrm{rmin}=$ & -0.1857 & & $\mathrm{rmin}=$ & -0.5345 & \\
\hline $\mathrm{r} \min 95$ & -0.1668 & $\begin{array}{l}95 \% \\
\text { confidence } \\
\text { interval, } \\
\text { min }\end{array}$ & $r \min 95$ & -0.3413 & $\begin{array}{l}95 \% \\
\text { confidence } \\
\text { interval, } \\
\text { min }\end{array}$ \\
\hline $\mathrm{r}$ ave & -0.0021 & Average & $\mathrm{r}$ ave & -0.0155 & Average \\
\hline $\mathrm{r} \max 95$ & 0.2528 & $\begin{array}{l}95 \% \\
\text { confidence } \\
\text { interval, } \\
\max \end{array}$ & $\mathrm{r} \max 95$ & 0.6051 & $\begin{array}{l}95 \% \\
\text { confidence } \\
\text { interval, } \\
\max \end{array}$ \\
\hline
\end{tabular}

naturally low substitution rate, a unique character in the $\operatorname{trn} \mathrm{L}-\mathrm{F}$ sequences is observed within the population of Mindoro. The restricted haplotype of the Mindoro population may be attributed to the geologic history of Mindoro, as the island was separated from the rest of the Philippines during the Pleistocene period (Heaney, 1986 as cited in Jones \& Kennedy, 2008). The isolation of Mindoro from the rest of the populations studied during the Pleistocene period may have enabled the Mindoro population to evolve independently, which may have led to its restricted haplotype.

The genetic diversity of 17 individuals across the six populations can be associated with the nine identified haplotypes in the ITS sequences. This is supported by the recombination and higher substitution rates that occur within nrDNA, thus increasing the variation among individuals, and allowing them to evolve quickly (Alvarez \& Wendel, 2003). The populations of Pangasinan and Aurora possess their own unique haplotypes. This suggests the lack of apparent gene flow for these populations, since they do not share common haplotypes with other populations. High haplotype diversity and low nucleotide diversity suggest that the populations recently diverged from each other, before the time period long enough to observe mutations that resulted to different haplotypes, but not long enough to accumulate mutations for bigger differences among sequences (Garg \& Mishra, 2017; Su et al., 2015).

For the ITS sequences, representatives from Cagayan, Marinduque, Mindoro, and Surigao share the same haplotype, which indicates that gene flow had occurred among these populations. This is contrary with the results of the number of haplotypes for the trnL-F region of I. macrophylla, suggesting that Mindoro had not exchanged genes with other populations and the haplotype acquired from gene flow is not shared among the individuals from Mindoro. This inconsistency may be attributed to the incongruence between chloroplast and nuclear datasets of the Philippine Ixora. Chloroplast DNA, which is maternally inherited, is used to explain the biogeography of the genus, as taxa with similar haplotypes may have originated from the same location. On the other hand, the biparentally-inherited nuclear DNA reflects the relatedness between taxa in an evolutionary sense (Banag et al., 2017).

The Pangasinan and Marinduque populations have shown to possess the least genetic diversity. This makes them more susceptible to inbreeding depression, which lowers the overall fitness of the populations. In addition, populations with lower genetic diversity are less capable of responding to environmental stresses. Therefore, these populations should be prioritized for conservation. They can be rescued by inducing anthropogenic gene flow into these populations to increase their genetic variation and reduce the occurrence of inbreeding depression (Waller, 2015).

\section{Mantel test}

The Mantel test is a statistical test that determines the correlation of genetic distance with geographical distances. Mantel test showed that these two variables are weakly correlated. The correlation coefficient, as represented by the diamonds, falls within the range of statistical confidence intervals (Fig. 3). Therefore, the genetic distances for the six populations studied cannot be attributed to isolation-by-distance, in which populations that are geographically closer are genetically more similar than populations that are farther apart (Mims et al., 2016). This is expected due to gene flow between 
Table 4. Genetic diversity of the two I. auriculata populations

\begin{tabular}{|c|c|c|c|c|c|c|c|c|c|c|}
\hline & A. $t r n \mathrm{~L}-\mathrm{F}$ & & & & & B. ITS & & & & \\
\hline Group & $\begin{array}{c}\text { No. of } \\
\text { sequences }\end{array}$ & $\begin{array}{c}\text { No. of } \\
\text { haplotypes }\end{array}$ & $\begin{array}{c}\text { haplotype } \\
\text { diversity } \\
\text { Hd }\end{array}$ & $\begin{array}{c}\text { Ave. no. of } \\
\text { differences, } \\
\text { K }\end{array}$ & $\begin{array}{l}\text { Nucleotide } \\
\text { diversity, pi }\end{array}$ & $\begin{array}{c}\text { No. of } \\
\text { sequences }\end{array}$ & $\begin{array}{c}\text { No. of } \\
\text { haplotypes }\end{array}$ & $\begin{array}{c}\text { haplotype } \\
\text { diversity } \\
\text { Hd }\end{array}$ & $\begin{array}{l}\text { Ave. no. of } \\
\text { differences, } \\
\text { K }\end{array}$ & $\begin{array}{l}\text { Nucleotide } \\
\text { diversity, pi }\end{array}$ \\
\hline Bulacan & 2 & 1 & 0.00000 & 0.00000 & 0.00000 & 2 & 2 & 1.00000 & 4.00000 & 0.00622 \\
\hline Romblon & 2 & 2 & 1.00000 & 1.00000 & 0.00127 & 2 & 2 & 1.00000 & 2.00000 & 0.00311 \\
\hline Total Data & 4 & 2 & 0.50000 & 0.50000 & 0.00063 & 4 & 4 & 1.00000 & 13.66667 & 0.02125 \\
\hline
\end{tabular}

populations, as inferred from the previous section (Feng et al., 2014). The correlation between the two variables is expected to increase by adding more samples from different localities to this study.

Aside from geographical range, other factors, such as dispersal capabilities, can influence the distribution of intraspecific genetic differentiation and gene flow. This is made possible by the long-distance seed dispersal by birds and mammals (Cain et al., 2000). Gravity seed-dispersal by birds and mammals has shown to be a factor in the genetic variation for Ammopiptanthus Cheng $f$. of the Leguminosae (Ge et al., 2005). Drupes can promote long-distance dispersal, as they may be the most specialized fruit type for bird dispersal (Bremer \& Eriksson, 1992). Frugivorous birds and small mammals that consume drupaceous fruits of Ixora can serve as dispersal vectors for the genus (De Block, 1998).

\section{Genetic diversity of I. auriculata}

The genetic diversity of the I. auriculata samples is represented by two different haplotypes of trnL-F and four distinct haplotypes of ITS. In agreement with the previous section, the lower number of haplotypes identified in trnL-F relative to that of ITS sequences is attributed to their substitution rates. A common haplotype for $\operatorname{trn} \mathrm{L}-\mathrm{F}$ is shared between the two populations, thus inferring that the two populations may have originated from the same mother population (Banag et al., 2017). Four haplotypes of ITS were identified for I. auriculata, with each haplotype unique to each individual. Therefore, the two populations of I. auriculata, at least for the samples utilized in the study, are genetically diverse. The absence of gene flow can be a major factor for the genetic differentiation between two populations (Feng et al., 2014).

The values for pairwise distances between the two populations of $I$. auriculata are notably high, with a mean distance of $3.05 \%$, as compared with the pairwise distances observed among I. macrophylla populations, whose distances peaked at only $0.9 \%$. This raises the question whether the two samples are conspecific. Several studies have utilized high genetic differentiation as one basis in determining whether samples are conspecific or not (Alejandro et al., 2007; Goodwillie \& Stiller, 2001; Shneyer \& Kotseruba, 2015). The high degree of genetic differentiation between the two populations of $I$. auriculata may suggest that these two are separate species, but the data presented are insufficient to support this claim. Phylogenetic analyses and more descriptive morphological examination of the two populations are necessary to reinforce this hypothesis.

\section{Conclusions and Recommendations}

The results of this study may serve as baseline information for further studies on I. macrophylla, and I. auriculata and may be useful in designing appropriate conservation strategies. It is recommended that more samples from other localities are collected to validate the genetic diversity of these species, and to re-evaluate the correlation of the genetic and geographic distances of the I. macrophylla samples. The high degree of genetic variation between the two populations of $I$. auriculata may suggest that the two samples are separate species. Further studies should focus on performing phylogenetic analyses and providing detailed morphological descriptions and comparisons of the two populations to support this claim.

\section{Acknowledgements}

The researchers would like to thank the following people who contributed to the success and completion of this study: Grecebio Jonathan D. Alejandro, Dr. rer. nat., the Research Center for Natural and Applied Sciences (RCNAS), the Thomasian Angiosperm Phylogeny and Barcoding Group (TAPBG), and Nikki Heherson Dagamac, Dr. rer. nat. 


\section{Literature Cited}

Alejandro, G.J.D., 2007. The current status of Philippine Rubiaceae. Philippine Journal of Systematic Biology, 1: 47 -60 .

Alejandro, G.J.D., J.P.C. Baysa, B.O.C. Lemana, G.M. Madulara, R.S. Madulid, \& D.A. Madulid, 2007. Conspecificity of Nepenthes alata Blco. population found in Mt. Guisguis, Zambales inferred from internal transcribed spacer (nrDNA) sequence data. Acta Manilana, 55: $15-21$.

Alvarez, I., \& J.F. Wendel, 2003. Ribosomal ITS sequences and plant phylogenetic inference. Molecular Phylogenetics and Evolution, 29: 417-434.

Amos, W., \& J. Harwood, 1998. Factors affecting levels of genetic diversity in natural populations. Philosophical Transactions of the Royal Society B: Biological Sciences, 353: 177-186.

Andreasen, K., B.G. Baldwin, \& B. Bremer, 1999. Phylogenetic utility of the nuclear rDNA ITS region in subfamily Ixoroideae (Rubiaceae): Comparisons with cpDNA $r b c \mathrm{~L}$ sequence data. Plant Systematics and Evolution, 217: 119135.

Banag, C.I., A. Mouly, G.J.D. Alejandro, B. Bremer, U. Meve, G.W. Grimm, \& S. Liede-Schumann, 2017. Ixora (Rubiaceae) on the Philippines - crossroad or cradle? BMC Evolutionary Biology, 17 (131): 1-16.

Bremer, B. \& O. Eriksson, 1992. Evolution of fruit characters and dispersal modes in the tropical family Rubiaceae. Biological Journal of the Linnean Society, 47: 79-95.

Brown, R.M., C.D. Siler, C.H. Oliveros, J.A. Esselstyn, A.C. Diesmos, P.A. Hosner, C.W. Linkem, A.J. Barley, J.R. Oaks, M.B. Sanguila, L.J. Welton, D.S. Blackburn, R.G. Moyle, A.T. Peterson, \& A.C. Alcala, 2013. Evolutionary processes of diversification in a model island archipelago. Annual Review of Ecology, Evolution and Systematics, 44: 411-435.

Cain, M.L., B.G. Milligan, A.E. Strand, 2000. Long-distance seed dispersal in plant populations. American Journal of Botany, 87: 1217-1227.

Chase, M.W., \& H.G. Hills, 1991. Silica gel: an ideal material for field preservation of leaf samples. Taxon, 40: 215-220.

Dalgleish, D., 2015. Contexture, excel tips, tutorials, and videos: Excel latitude and longitude calculations. http:// www.contextures.com/excellatitudelongitude.html.

Accessed 21 March 2018.

Davis, A., R. Govaerts, D. Bridson, M. Ruhsam, \& N. Brummitt, 2009. A global assessment of distribution, diversity, endemism, and taxonomic effort in the
Rubiaceae. Annals of the Missouri Botanical Garden, 96: 68 -78 .

De Block, P., 1998. The African species of Ixora (RubiaceaePavetteae). Opera Botanica Belgica, 9: 1-218.

Dong, W., J. Liu, J. Yu, L. Wang, \& S. Zhou, 2012. Highly variable chloroplast markers for evaluating plant phylogeny at low taxonomic levels and for DNA barcoding. PLoS ONE, 7: e35071

Feng, X., Y. Wang, \& X. Gong, 2014. Genetic diversity, genetic structure, and demographic history of Cycas simplicipinna (Cycadaceae) assessed by DNA sequences and SSR markers. BMC Plant Biology, 14 (187): 1-16.

Frankham, R., 2005. Genetics and extinction. Biological Conservation, 126: 131-140.

Garg, R.K., \& V. Mishra, 2018. Molecular insights into the genetic and haplotype diversity among four populations of Catla catla from Madhya Pradesh revealed through mtDNA cyto $b$ gene sequences. Journal of Genetic Engineering and Biotechnology, 16: 169-174.

Gaticales, C.A., E.G. Gonzales, J.K. Marquez, \& G.L. Montalbo, 2016. Genetic diversity of Ixora macrophylla with a preliminary report of phytochemical components. Undergraduate thesis, University of Santo Tomas, Manila.

Ge X., Y. Yu, Y. Yuan, H. Huang, \& C. Yan, 2005. Genetic diversity and geographic differentiation in endangered Ammopiptanthus (Leguminosae) populations in desert regions of northwest China as revealed by ISSR analysis. Annals of Botany, 95: 843-851.

Goodwillie, C. \& J.W. Stiller, 2001. Evidence for polyphyly in a species of Linanthus (Polemoniaceae): Convergent evolution in self-fertilizing taxa. Systematic Botany, 26: 273-282.

Hague, M.T.J., \& E.J. Routman, 2016. Does population size affect genetic diversity? A test with sympatric lizard species. Heredity, 116: 92-98.

Heaney, L.R., 1986. Biogeography of mammals in SE Asia: Estimates of rates of colonization, extinction, and speciation. Biological Journal of the Linnean Society, 28: 127-165.

Hood, G.M., 2010. PopTools version 3.2.5. http:// www.poptools.org. Accessed 1 April 2014.

Jones, A.W., \& R.S. Kennedy, 2008. Evolution in a tropical archipelago comparative phylogeography of Philippine fauna and flora reveals complex patterns of colonization and diversification. Biological Journal of the Linnean Society, 95: 620-639.

Librado, P., \& J. Rozas, 2009. DnaSP v5: a software for comprehensive analysis of DNA polymorphism data. Bioinformatics, 25: 1451-1452. 
Maddison, W.P., \& D.R. Maddison, 2018. Mesquite: A modular system for evolutionary analysis. Version $3.51 \mathrm{http} / /$ www.mesquiteproject.org

Maki, M., T. Yamashiro, \& S. Matsumura, 2003. High levels of genetic diversity island populations of the island endemic Suzukia luchuensis (Labiatae). Heredity, 91: 300-306.

Mason-Gamer, R.J., K.E. Holsinger, \& R.K. Jansen, 1995. Chloroplast DNA haplotype variation within and among populations of Coreopsis grandiflora (Asteraceae). Molecular Biology and Evolution Society, 12: 371-381.

Mims, M.C., L. Hauser, C.S. Goldberg, \& J.D. Olden, 2016. Genetic differentiation, isolation-by-distance, and metapopulation dynamics of the Arizona treefrog (Hyla wrightorum) in an isolated portion of its range. PLoS One, 11: $\mathrm{e} 0160655$.

Myers, N., R.A. Mittermeier, C.G. Mittermeier, G.A.B. da Fonseca, \& J. Kent, 2000. Biodiversity hotspots for conservation priorities. Nature, 403: 853-858.

Pelser, P.B., J.F. Barcelona \& D.L. Nickrent (eds.). 2011 onwards. Co's Digital Flora of the Philippines. www.philippineplants.org

Popp, M. \& B. Oxelman. 2001. Inferring the history of the polyploid Silene aegaea (Caryophyllaceae) using plastid and homoeologous nuclear DNA sequences. Molecular Phylogenetics and Evolution, 20: 474-481.

Rao, R.V., \& T. Hodgkin, 2001. Genetic diversity and conservation and utilization of plant genetic resources. Plant Cell, Tissue and Organ Culture, 68: 1-19.

Shneyer, V.S., \& V.V. Kotseruba, 2015. Cryptic species in plants and their detection by genetic differentiation between populations. Russian Journal of Genetics: Applied Research, 5: 528-541.

Su, L.N., X.C. Li, H.Z. Meng, X.Y. Gao, H. Yin, \& H. Li, 2015. Population genetic structure and historical demography of the ground beetle Chlaenius costiger in the TsinlingDabashan Mountains of central China. Genetics and Molecular Research, 14: 3579-3589.

Taberlet, P., G. Ludovic, G. Pautou, \& J. Bouvet, 1991. Universal primers for amplification of three non-coding regions of chloroplast DNA. Plant Molecular Biology, 17: 1105-1109.

Tamura K., G. Stecher, D. Peterson, A. Filipski, \& S. Kumar, 2013. MEGA6: Molecular Evolutionary Genetics Analysis version 6.0. Molecular Biology \& Evolution, 30: 27252729.

Templeton, A.R., 2004. Using haplotype trees for phylogeographic and species inference in fish populations. Environmental Biology of Fishes, 69: 7-20.

Waller, D.M., 2015. Genetic rescue: a safe or risky bet?
Molecular Ecology, 24: 2595-2597 